Journal of Physical Science, Vol. 29(Supp. 2), 147-157, 2018

\title{
The Implementation of Fuzzy Expert Systems on Concrete Bridge Investigation with Octave
}

\author{
Setiono*, Wibowo and Sofa Marwoto \\ Department of Civil Engineering, Sebelas Maret University Surakarta, \\ Jawa Tengah 57126, Indonesia \\ *Corresponding author: setiono@ft.uns.ac.id
}

Published online: 30 July 2018

To cite this article: Setiono, Wibowo \& Marwoto, S. (2018). The implementation of fuzzy expert systems on concrete bridge investigation with Octave. J. Phys. Sci., 29(Supp. 2), 147-157, https://doi.org/10.21315/jps2018.29.s2.11

To link to this article: https://doi.org/10.21315/jps2018.29.s2.11

\begin{abstract}
Bridge is an infrastructure that has an important role in economic activities of the community. Throughout its service period, a bridge experiences various problems due to environmental factors and traffic loads. This study is focused on investigating the conditions of concrete bridge infrastructure in Surakarta, Indonesia based on fuzzy expert system method developed with Octave open source software as tool. This study is conducted by building a fuzzy expert system application based on bridge members' conditions to obtain overall level performance of the bridge. In general, this research is divided into three parts. Firstly, to conduct surveys of several bridges conditions as sample data for application. Secondly, to build a model of fuzzy membership function and fuzzy inference engine for each type of bridge condition. Thirdly, to develop an application of fuzzy expert system based on the model developed with Octave. The result of the research can be used in an expert system application to determine the condition level of the bridges.
\end{abstract}

Keywords: Bridge investigation, concrete bridge, fuzzy expert systems, Octave, Surakarta

\section{INTRODUCTION}

Surakarta is an important city and is one of Indonesia's national economic centres, especially in Central Java. In the last few decades, the growth rate of the transportation sector, including in the city of Surakarta, has shown a marked increase. This is evidenced by the increasing number of automotive transportation facilities with annual growth of more than $10 \%$ or 22,534 vehicles per year. ${ }^{1,2}$ With 
the increasing number of public transportation services, availability of reliable transportation infrastructure is necessary.

One of the primary transportation infrastructures in our life is bridge. As a bridge has an important role in sustainability of infrastructure network, it is necessary to ensure its service and functions are within expectation. It is important to maintain its performance during the planned service life to prevent incidents that may shorten its service period. A bridge built to last 25 years of service, for example, may only perform optimally for only 10 years due to unforeseen circumstances.

Surakarta has more than one hundred bridges connecting transportation network for internal and external routes. Most of them are simple slab concrete bridges. According to guidelines issued by the Indonesia's Ministry of Public Work, a concrete bridge has two main components in supporting its performance: upper structure and substructure. The upper structure contains deck/slab and beam, whereas the substructure has foundation and pillar components, including abutments. For certain reasons, the bridge investigation is conducted in a simple way rather than using the Bridge Management Systems (BMS) module. ${ }^{3,4}$ An inspector observes the visual aspects of a bridge such as crack or deflection of the bridge members. ${ }^{5}$ Previous research has faced problems when implemented in the field area due to shortage of resources, quality of inspector, tools required and high expense, although they promise an accurate results. ${ }^{6,7}$ The form of investigation is designated to collect the general data of a bridge and some visual observations with six level (levels 0 to 5) of conclusions: very good, good, moderate, bad, very bad, and collapse. ${ }^{3}$ Each bridge component has particular damage behaviours different from others. For instance, a beam has weakness in deflection, while a pillar has flexural/horizontal deformation. The important indicator is that if any component has a level-5 damage, the overall bridge structures are at the point of collapsing.

Octave, a freeware mathematical program, provides a fuzzy logic algorithm module. Fuzzy logic is an approach to solve problems that have uncertainty in their values or a range of values. Considering the research problems, i.e., structures of concrete bridges, this approach is the most suitable among others.

Previous studies relating to fuzzy logic for concrete bridge damage were done by Setiono and Sofa Marwoto using the Delphi programming language and BMS as a reference. The developed software, however, was difficult to apply because due to its detailed complexity and requirements of big data. ${ }^{6,7}$ 


\section{LITERATURE REVIEW}

\subsection{Octave}

GNU Octave is a high-level language intended for numerical computations. It provides a convenient command line interface for solving linear and nonlinear problems numerically, and for performing other numerical experiments using a language compatible with Matlab. It may also be used as a batch-oriented language.

Octave has extensive tools for solving common numerical linear algebra problems, finding the roots of nonlinear equations, integrating ordinary functions, manipulating polynomials, and integrating ordinary differential and differentialalgebraic equations. It is easily extensible and customisable via user-defined functions written in Octave's own language, or using dynamically loaded modules written in $\mathrm{C}++, \mathrm{C}$, Fortran or other languages. ${ }^{8}$

\subsection{Fuzzy Logic}

A fuzzy logic can be considered as an approach to map an input space into an output space. This logic operates a fuzzy set to get the expected output. The fuzzy set can be defined as a class/category of objects with values or degree of membership that is continuum (continuous). This set accommodates reality which appears in the real physical world where often criteria/values obtained cannot be clearly/exact value and is at a range curve value. Fuzzy concept accommodates some truth, where the correct value (one value that signifies that a statement is true) is between completely true and completely false. In classical logic theory, the only possible truth is true (true) or false, but theory fuzzy logic allows more true values in the range between true (true) to false. The most important application of fuzzy system (fuzzy logic) is in uncertain issues. When a problem has a dynamic behaviour, fuzzy logic is a suitable tool dealing with this problem. ${ }^{9}$

\section{RESEARCH METHOD}

\subsection{Location}

This research takes place in Surakarta city with five concrete bridges as the research subjects in building the model of fuzzy expert systems. The markers on the Figure 1 show the location of bridges of this study in Google Maps view. 


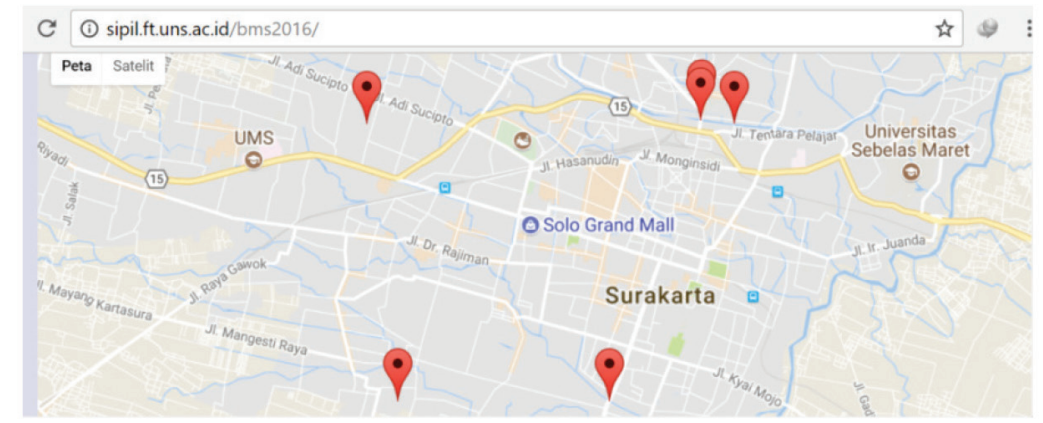

Figure 1: The location of research (source: result of the research).

Table 1: The list of five bridges in Surakarta as subject of the research.

\begin{tabular}{llcccc}
\hline \multirow{2}{*}{$\begin{array}{l}\text { Name of } \\
\text { bridge }\end{array}$} & Street & Year built & \multicolumn{3}{c}{ Dimension (m) } \\
\cline { 4 - 6 } & & 1960 & 76.0 & 5.8 & 5 \\
\hline Maris & Jl. Walanda Maramis & 1980 & 8.0 & 9.7 & 1 \\
Nayu & Jl. Letjen Sutoyo & 1980 & 22.4 & 7.2 & 2 \\
Transito & Jl. Griyan Transito & 1970 & 21.7 & 15.8 & 2 \\
Jongke & Jl. Dr. Rajiman & 1970 & 17.2 & 16.9 & 1 \\
Kajen & Jl. Yos Sudarso & & & & Width \\
\hline
\end{tabular}

Table 1 indicates that most of the bridges have been around for more than 30 years. Their lengths vary from $17.2 \mathrm{~m}$ to $76 \mathrm{~m}$ and the spans range between 1 and 5 . The numbers indicate that the bridges are potentially operating at low-performance condition.

\subsection{Fuzzy Inference Systems}

The fuzzy approach used in this research is in accordance to Mamdani method, i.e., the output of defuzzyfication representing crisp value, a method built for a fuzzy systems to control a steam engine and boiler combination based on experienced human operator. ${ }^{10}$

There are generally four steps in applying fuzzy inference systems: develop input of real world facts as fuzzy sets; build rule evaluation; aggregate the rule outputs; and defuzzyficate to get the final result. Figure 2 shows the second process to four steps of fuzzy inference systems using Mamdani method. 


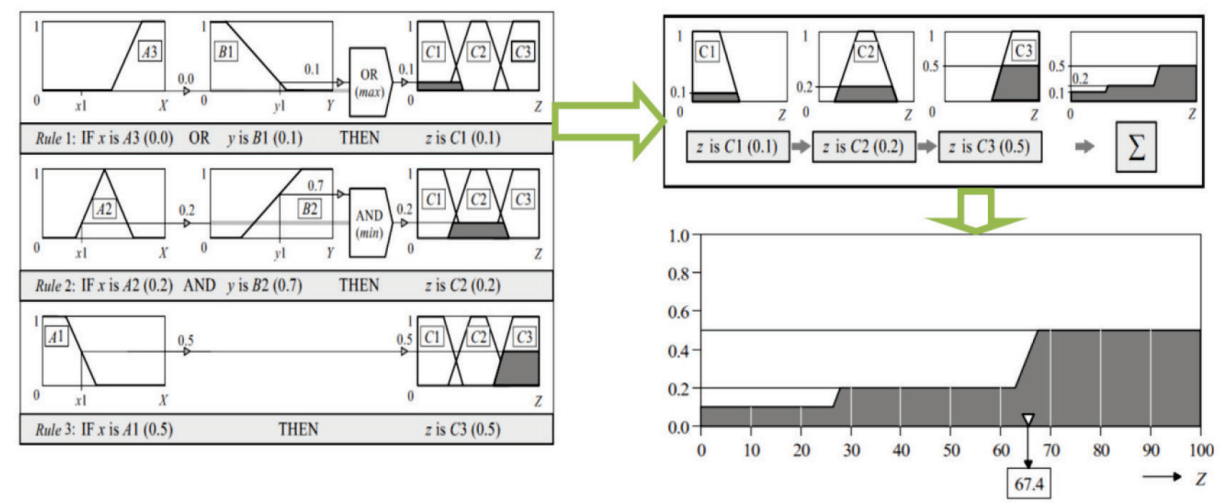

Figure 2: Example of the Mamdani data flow style rule evaluation, aggregation of the result, defuzzyfication. ${ }^{10}$

\section{RESULTS AND DISCUSSION}

\subsection{Proportion of Concrete Bridge Components}

According to the Ministry of Public Works, the capability of a bridge is distributed across five major components, i.e., deck, beams, parapet, foundation and pillar/ abutments. ${ }^{3}$ In this research, as the foundation components are located underground, and the behaviour related to pillar/abutment cannot be observed, they are ignored in the calculation. Accordingly, the parapet is also ignored. To determine how much a component contributes/supports performance of a complete concrete bridge, a survey has been undertaken with several experts in bridge structures as respondents. The main support components are presented in Table 2. Each proportion becomes a final multiplication factor to the result of each fuzzy process. The biggest proportion is found to be at the beam, while the least is the deck. 
Table 2: The proportion of concrete bridges components support.

\begin{tabular}{ll}
\hline Components & Proportions for overall bridge capability \\
\hline Beam & $33.75 \%$ \\
Deck & $16.25 \%$ \\
Pillar & $25.00 \%$ \\
Abutment & $25.00 \%$ \\
\hline
\end{tabular}

\subsection{Membership Functions}

In developing membership function for each component of a concrete bridge, the types of damage are chosen based on the major damage that can lead to bridge component collapsing and the damage visually can be observed; a beam is critical in deflection and crack with the maximum deflection value of $6.25 \%$ and crack of $10 \%$. The deck has both crack and spalling, maximum at $10 \%$. The pillar and abutment have the same factors, i.e., settlement and pop out, but the values are 10 $\mathrm{cm}$ and $10 \%$ for pillars, and $5 \mathrm{~cm}$ and $10 \%$ for the abutment. The input membership function for each factor is divided into five categories: very low (VL), low (L), medium (M), high $(\mathrm{H})$ and very high $(\mathrm{VH})$. Meanwhile, the membership function for output is categorised into 5: very bad (VB), bad (B), medium (M), good (G) and very good (VG).

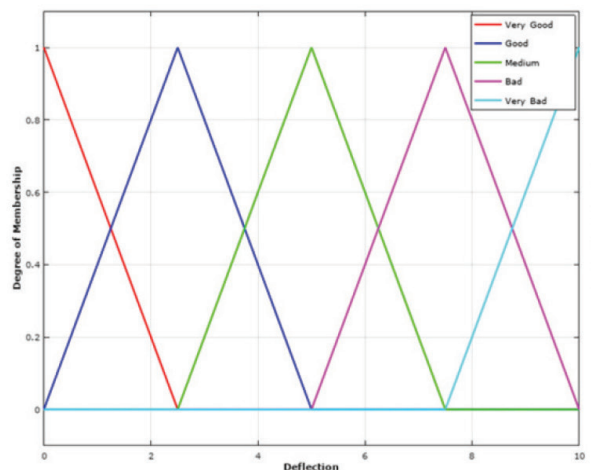

(a)

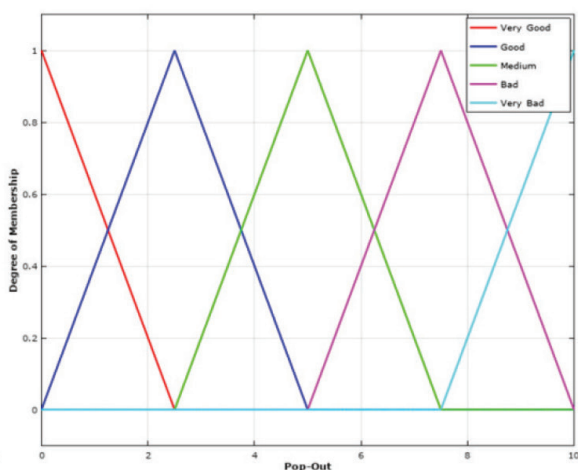

(b)

Figure 3: Membership function for pillar, with (a) deflection, and (b) pop-out. 


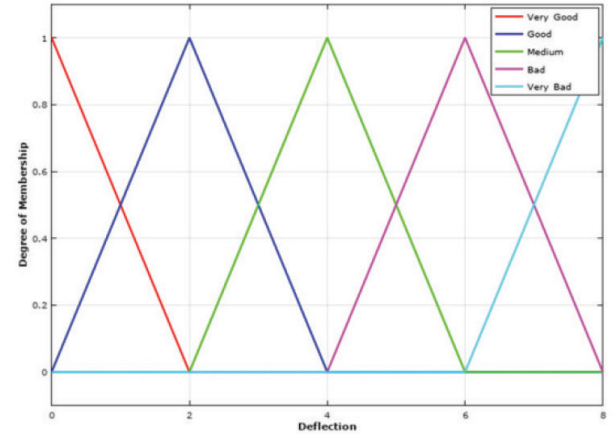

(a)

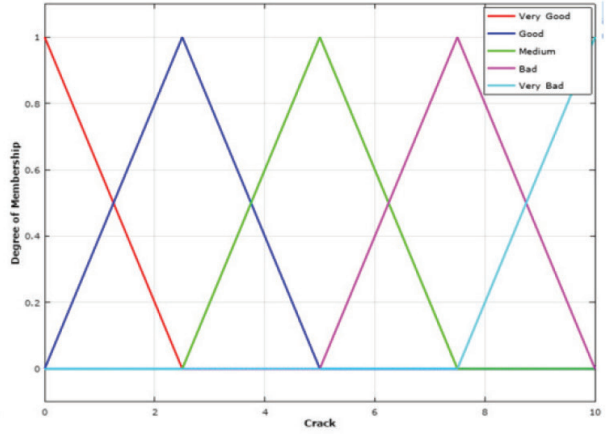

(b)

Figure 4: Membership function for beam with (a) deflection, and (b) crack.

Figures 3 to 7 show the graphical membership function for the input of each bridge component. Figure 7 is graphical membership function for output. It ranges from $0 \%$ to $100 \%$, from lowest level of bridge condition to its highest level. Octave is used as the fuzzy logic toolkit.

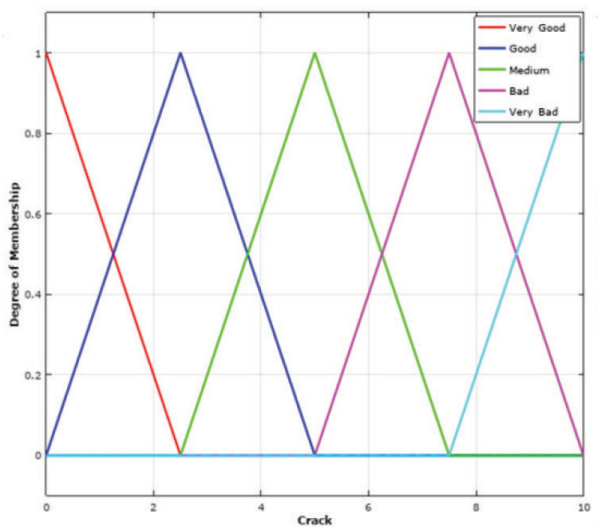

(a)

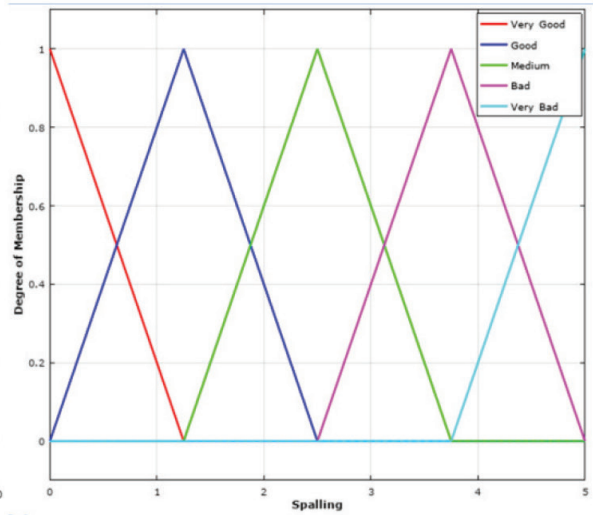

(b)

Figure 5: Membership function for deck, with (a) crack, and (b) spalling. 


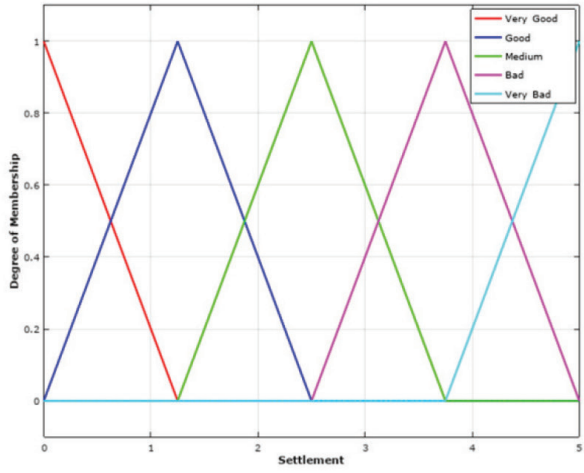

(a)

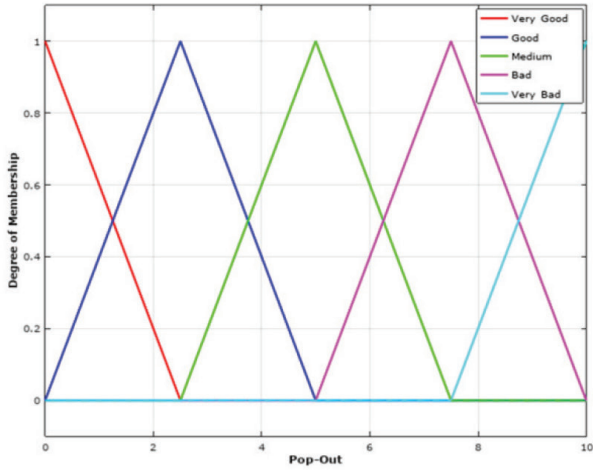

(b)

Figure 6: Membership function for abutment, with (a) settlement, and (b) pop-out.

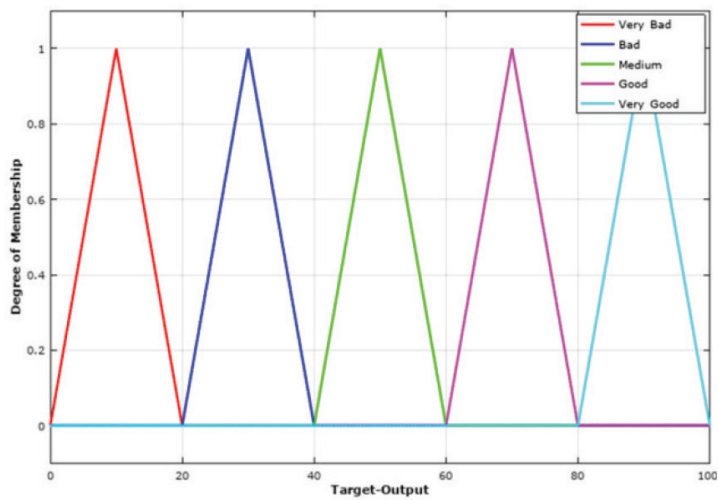

Figure 7: Membership function for output (all components).

\subsection{Rule Base}

The rule base is the main part of the Fuzzy Inference System (FIS), and the quality of results in the fuzzy system depends on the fuzzy rules. A procedural reasoning known as the compositional rule of inference enables conclusion to be drawn by generalisation from the qualitative information stored in the knowledge base. ${ }^{9}$ The following table summarises part of the rule base for all components, with each component has 25 rule bases. Accordingly, the rest of components have the same pattern as the table. 
Table 3: Rule base for pillar.

\begin{tabular}{lccc}
\hline Order of rule & \multicolumn{2}{c}{ Input } & Output \\
\hline 1 & Deflection & Pop-out & \\
\hline 2 & VL & VL & VG \\
3 & VL & L & G \\
4 & VL & M & G \\
5 & VL & H & M \\
$\ldots$ & VL & VH & B \\
25 & $\ldots$ & $\ldots$ & $\ldots$ \\
\hline
\end{tabular}

\subsection{Final Result}

Table 4 shows the input for the model according to visual observation in the field. For the 5 bridges investigated, there are various values of deterioration, but all bridges have the same deflection at beam, i.e., zero value. Each pair of component data was then inputted into the systems developed using rule base described in Table 3.

Table 4: The input pair of concrete bridges components.

\begin{tabular}{lcccccccc}
\hline \multirow{2}{*}{ Bridges } & \multicolumn{7}{c}{ Damage type bridge components } \\
\cline { 2 - 9 } & \multicolumn{2}{c}{ Beam } & \multicolumn{2}{c}{ Deck } & \multicolumn{2}{c}{ Pillar } & \multicolumn{2}{c}{ Abutment } \\
\hline \multirow{2}{*}{ Maris } & 0 & 10 & 10 & 10 & 2 & 5 & 4 & 10 \\
Nayu & 0 & 5 & 2 & 2 & 2 & 10 & 2 & 10 \\
Transito & 0 & 3 & 5 & 7 & 0 & 5 & 2 & 5 \\
Jongke & 0 & 2 & 2 & 2 & 0 & 5 & 2 & 5 \\
Kajen & 0 & 3 & 2 & 2 & 0 & 3 & 2 & 5 \\
\hline
\end{tabular}

Table 5 shows the rating of bridges observed based on the given rule base in Table 3. The final result of each component is multiplied by the proportion shown in Table 2 which results in the rating for the bridge as a whole. The rating values, consequently, are translated into language based on the output model of fuzzy expert systems. 
Table 5: Rating of the concrete bridges observed.

\begin{tabular}{|c|c|c|c|c|c|c|}
\hline \multirow{3}{*}{ Bridges } & \multicolumn{4}{|c|}{ Bridge components proportion } & \multirow{3}{*}{ Rating } & \multirow{3}{*}{ Meaning } \\
\hline & Beam & Deck & Pillar & Abutment & & \\
\hline & $33.75 \%$ & $16.25 \%$ & $25 \%$ & $25 \%$ & & \\
\hline Maris & 50.00 & 10.00 & 35.45 & 30.00 & 34.86 & $\mathrm{Bad}$ \\
\hline Nayu & 10.00 & 49.13 & 35.45 & 30.00 & 27.72 & Bad \\
\hline Transito & 64.94 & 16.37 & 39.09 & 50.00 & 46.85 & Medium \\
\hline Jongke & 75.45 & 60.48 & 39.09 & 50.00 & 57.56 & Good \\
\hline Kajen & 53.63 & 37.14 & 39.09 & 50.00 & 46.41 & Medium \\
\hline
\end{tabular}

Based on Table 5, it can be seen that two bridges are operating at a bad level and need immediate attention. Two other bridges, meanwhile, are in medium condition that also require attention in the next coming few years. Another bridge has a good rating but still requires routine check to ensure that the bridge is operating at optimal service.

\section{CONCLUSION}

In this work, a model for bridge investigation based on fuzzy expert systems has been developed and applied. From the five bridges observed, two bridges showed a bad rating, two others are in medium condition, and one is operating at a good level but it still requires routine check for optimal service. Based on the built date of bridges observed, it can be generally accepted that bridges have low rating after a length of service of longer than 30 years.

\section{ACKNOWLEDGEMENTS}

The authors would like to acknowledge the Sebelas Maret University Surakarta, Indonesia which has given support and funding during this research through research scheme Maintenance Research Group (MRG) with grant number: $623 / \mathrm{UN} 27.21 / \mathrm{PP} / 2017$. We also appreciate support from the personnel in the Department of Civil Engineering, Sebelas Maret University Surakarta, who have shared their knowledge to improve the quality of the result of this research. Lastly, we thank all students who have helped in data collection. 


\section{REFERENCES}

1. Kontan. (2017). Di Solo pertumbuhan kendaraan capai $15 \%$ per tahun. Retrieved 1 January 2017, http://regional.kontan.co.id/news/di-solopertumbuhan-kendaraan-capai-15-per-tahun.

2. The Solopos. (2017). Setahun, ada tambahan 22.534 unit kendaraan baru di Solo. Retrieved 1 January 2017, http://www.solopos.com/2017/01/05/ transportasi-solo-setahun-kendaraan-baru-bertambah-22-534-unit-781784.

3. Ministry of Public Works Indonesia. (2015). Pedoman pemeriksaan inventarisasi jembatan. Retrieved 10 January 2017 from http://www.pu.go. $\mathrm{id} /$ uploads/services/service20130717122013.pdf.

4. Directorate General of Highways. (1993). Bridge Management Systems. Jakarta: Ministry of Public Works Indonesia.

5. Kuchekar, C. \& Deshpande, U. (2017). Visual inspection of concrete bridge. Inter. J. Innov. Eng. Res. Tech., 4(3), 125-127.

6. Setiono \& Marwoto, S. (2010). Pemodelan logika fuzzy terhadap kerusakan Jembatan Beton. Media Teknik Sipil, 10(1), 28-35.

7. Marwoto, S., Suprapto, M. \& Syafi'i. (2014). Pemodelan sistem pendukung keputusan untuk pemeliharaan Jembatan Beton. Jurnal Teknik Sipil, 1(1), $75-80$.

8. Octave. (2017). About GNU Octave. Retrieved 1 January 2017, https:// www.gnu.org/software/octave/about.html.

9. Nesat, M. \& Adeli, A. (2011). Designing a fuzzy expert system to predict the concrete mix design. Paper presented at the IEEE International Conference on Computational Intelligence for Measurement Systems and Applications Proceedings.

10. Chinnasarn, K. (2017). Introduction to AI. Retrieved 5 January 2017 from https://staff.informatics.buu.ac.th/ krisana /975352/. 